\title{
En kvinne i 40-årene med anisokori og ensidig ansiktsrødme
}

\author{
En ellers frisk kvinne i 40-årene ble henvist til nevrologisk vurdering \\ grunnet nyoppstått anisokori. Etter hvert fremkom det at hun også \\ fikk ensidig ansiktsrødme ved anstrengelse. Systematisk tilnærming \\ og kjennskap til sympatisk og parasympatisk anatomi var nyttig i den \\ diagnostiske avklaringen.
}

Kvinnen ble henvist til nevrologisk akuttpoliklinikk grunnet to ukers sykehistorie med anisokori. 15 år tidligere hadde hun hatt tilbakevendende iridosyklitt på begge øynene. Hun var ellers frisk og brukte ingen medisiner.

Fysiologisk anisokori forekommer hos om lag $20 \%$ av befolkningen (1). Andre årsaker til anisokori er øyesykdom, affeksjon av parasympatikus eller sympatikus eller sykdommer i sentralnervesystemet (ramme 1) (2). Sympatikusdefekt gir miose (liten pupill) og parasympatikusdefekt gir mydriasis (stor pupill).

Ved klinisk undersøkelse av anisokori må man først finne ut hvilken pupill som er unormal. Et tips er å undersøke pasienten i dunkel belysning. Vanligvis dilaterer pupillene i mørket, så hvis forskjellen i størrelse øker i dunkel belysning, tyder det på at den minste pupillen har en sympatikusdefekt

\section{RAMME 1}

Årsaker til anisokori (2)

Lokal sykdom i øyet

- Traume

- Iritt

- Iskemi i iris

Parasympatikusdefekt (mydriasis)

- Okulomotoriusparese

- Tonisk pupill (Adies pupill)

- Farmakologisk mydriasis

Sympatikusdefekt (miose)

- Horners syndrom

Enkel anisokori

- Fysiologisk anisokori

Årsaker i sentralnervesystemet

- Vaskulært

- Tumor

- Herniering

- Infeksjon (bla syfilis) som forhindrer dilatasjon. Et annet tips er å dryppe med apraklonidin øyedråper. Pupilldilatasjon etter drypping tyder på sympatikusdefekt og adrenerg hypersensitivitet (3).

Hos vår pasient fant vi at venstre pupill var større enn den høyre. Anisokorien økte ikke når det var mørkt, det var ikke ptose, og venstre pupill reagerte dårlig på direkte og indirekte lys, men kontraherte ved nærinnstilling.

Vi mente sympatikusdefekt, som ved Horners syndrom, var så lite sannsynlig at det ikke var indikasjon for apraklonidintest. Det var ingen lammelse av de ytre øyemusklene. Generell nevrologisk undersøkelse var normal, inklusive reflekser, og vi kunne med høy sannsynlighet slå fast at pasienten hadde isolert venstresidig mydriasis.

Mydriasis kan skyldes lokal eksponering for et antikolinergikum (atropin eller skopolamin), for eksempel ved bruk av av øyedråper eller reisesykeplaster, eller ved håndtering av medikamentet morfin-skopolamin. Slik eksponering kan gi dilatert pupill i opptil to uker (4). Andre mulige årsaker er skade eller sykdom i øyet.

Vi intervjuet pasienten grundig om mulige farmakologiske årsaker til tilstanden, men hun benektet å ha vært i kontakt med atropin. Hun hadde ingen andre symptomer fra øyet, og undersøkelse hos øyelege var normal. Orienterende blodprøver, inkludert serologisk prøve for syfilis, blodsukker- og kolesterolnivå, var normale.

Mydriasis kan også skyldes svikt i tilførende parasymatiske nervefibre. Preganglionære parasympatiske fibre ligger overflatisk i n. oculomotorius, mens de motoriske fibre til ytre øyemuskler ligger dypere. Mekanisk trykk mot nerven kan derfor gi isolert mydriasis.

Hos pasienter med redusert bevissthet kan ensidig mydriasis være tegn på økt intrakranialt trykk og begynnende herniering. Isolert

\author{
Lars Jørgen Garstad \\ lars.jorgen.garstad@sshf.no \\ Nevrologisk avdeling \\ Sørlandet sykehus, Kristiansand \\ Åse Mygland \\ Nevrologisk avdeling \\ Sørlandet sykehus, Kristiansand \\ og \\ Avdeling for rehabilitering \\ Sørlandet sykehus, Kristiansand \\ og \\ Klinisk institutt 1 \\ Universitetet i Bergen \\ Unn Ljøstad \\ Nevrologisk avdeling \\ Sørlandet sykehus, Kristiansand \\ og \\ Klinisk institutt 1 \\ Universitetet i Bergen
}




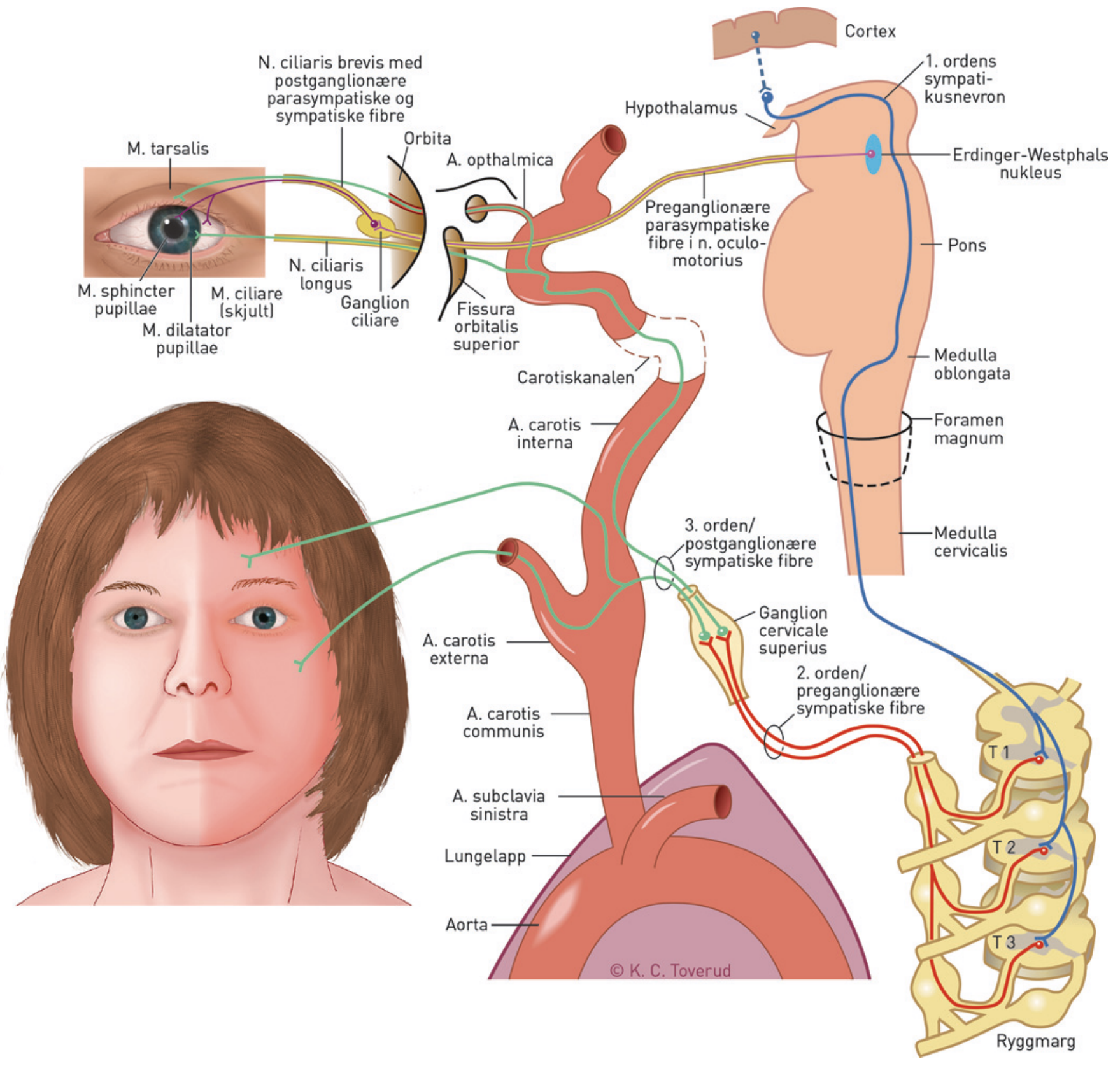

Figur 1 Ved fysisk stress ble pasienten rød kun på den ene siden av ansiktet. Her er en skjematisk fremstilling av sympatiske og parasympatiske fibre til ansikt og øye. Sympatikus: Preganglionære fibre til øyet lokulosympatiske) forlater ryggmargen i første torakale nivå, mens fibre som regulerer svette (sudomotoriskel og blodårene i huden (vasomotoriske) i ansiktet forlater ryggmargen i andre og tredje torakale nivå. Ganglion cervicale superius ligger i nær relasjon til carotisbifurkaturen, columna vertebralis, lungetoppen, øvre ribben, thyroidea og arteria og vena subclavia. Postganglionære vaso- og sudomotoriske fibre til panne og nese og fibre til øyet går langs a. carotis interna, mens vaso- og sudomotoriske fibre til nedre del av ansiktet går langs a. carotis externa. Parasympatikus: Preganglionære fibre går via n. oculomotorius til ganglion ciliare og postganglionære fibre går via n. ciliaris brevis

mydriasis hos våkne pasienter uten andre nevrologiske symptomer kan skyldes trykk mot n. oculomotorius fra aneurisme, aberrant karforløp eller tumor (5).

For å utelukke aneurisme ble det tatt CTundersøkelse av hodet med CT angio, som viste normale forhold. Vi fortsatte derfor utredningen for å finne årsaken til pasientens mydriasis.
For å bekrefte mistanken om parasympatikusdefekt gjorde vi en pilokarpintest (drypping med pilokarpin $0,1 \%$ ). Normale pupiller kontraherer tydelig ved eksponering for pilokarpin $2 \%$, men ubetydelig ved eksponering for fortynnet pilokarpin.

Ved parasympatikusdefekt, derimot, oppstår det kolinerg hypersensitivitet, og pupillen vil kontrahere ved eksponering for pilokarpin som er fortynnet til $0,1 \%(6)$.
Ved pilokarpintest ble den venstre dilaterte pupillen mindre, men ikke den høyre. Tentativ diagnose var da Adies pupill.

Adies pupill kjennetegnes av en dilatert pupill som reagerer langsomt på lysstimuli, men som ofte reagerer bedre ved testing av nærinnstilling (lys-nær-dissosiasjon). Pilokarpintest er positiv hos om lag $80 \%$ (7). Adies pupill skyldes patologiske forhold i 
ganglion ciliare (fig 1), som er lokalisert i bakre orbita og avgir postganglionære fibre til $\mathrm{m}$. sphincter pupillae, som sørger for pupillkonstriksjon, og til $\mathrm{m}$. ciliare, som sørger for krumming av linsen ved akkomodasjon.

Etter skade i ganglion ciliare oppstår ofte aberrant reinnervasjon, og ved testing av nærrespons, som normalt aktiverer $\mathrm{m}$. ciliare, aktiveres isteden m. sphincter pupillae. Adies pupill er oftest idiopatisk og regnes som en benign tilstand. Vi tenkte at utredningen kunne avsluttes, men så kom det en litt overraskende ekstraopplysning.

Pasienten fortalte at hun i noen år var blitt rød bare på venstre side av ansiktet ved fysisk anstrengelse, mens hun ved emosjonelt stress ble rød på begge sider (fig 1).

Avbrutt sympatisk innervasjon til ansiktet vil ofte gi ipsilateral blekhet og manglende svetteutsondring (hemifacial anhidrose) (8, 9), men det man ofte legger merke til er den kontralaterale rødmen og svetten som blir ekstra kraftig for å opprettholde normal varmeregulering i ansiktet (10). Hemifacial anhidrose kalles gjerne Harlekins tegn (11).

Vår pasient hadde venstresidig Adies pupill, forårsaket av en parasympatikusdefekt i ganglion ciliare, og høyresidig hemifacial anhidrose forårsaket av sympatikusdefekt. Vi klarte ikke å fastslå den anatomiske lokaliseringen av sympatikusdefekten. Fravær av hemifacial anhidrose ved emosjonelt stress kan tyde på affeksjon av første ordens nevron (11), mens manglende Horners syndrom kan tyde på affeksjon av andre ordens nevron (preganglionært) i 2. og 3. torakale rot eller i nedre del av den sympatiske grensestreng (9) (fig 1).

MR caput og totalmedulla og røntgen thorax var normale. Pasienten hadde normale reflekser. Hun var aktiv mosjonist, i full jobb, uten symptomer på ortostatisme, derfor gjorde vi ikke flere tester på generell autonom svikt.

Adies pupill kan være assosiert med hyporefleksi og kalles da Holmes-Adies syndrom, mens samtidig Adies pupill, hyporefleksi og segmental anhidrose kalles Ross' syndrom (12).

Pasienten hadde normale reflekser og derfor ikke et klassisk Ross' syndrom. Vi valgte å stille symptomdiagnosen primær partiell dysautonomi. Erfaring fra Ross' syndrom og andre partielle dysautonomier er at veldig sakte progrediering kan forekomme, men at tilstandene er benigne. Det finnes ingen kausal behandling.

\section{Diskusjon}

Den første som beskrev den klassiske triaden Adies pupill, hyporefleksi og segmental anhidrose, var Ross - i 1958 (13). Siden den gang har det vært beskrevet om lag 40 pasienter med Ross' syndrom (14). De første som beskrev Harlekins tegn var Lance og medarbeidere i 1988 (15), og om lag 120 pasienter er beskrevet siden.

Det synes imidlertid ikke å være noen klar distinksjon mellom tilstandene, og i litteraturen presenteres flere pasienter med ulike kombinasjoner av Harlekins tegn, Horners syndrom, Adies pupill, Holmes-Adies syndrom og Ross' syndrom $(12,16,17)$. I en pasientserie fra 2000 hadde fire av fem pasienter med klassisk Ross' syndrom samtidig postganglionært Horners syndrom (12). I en annen pasientserie fra 2008 hadde 25 av 39 grundig undersøkte pasienter med Harlekins tegn pupillabnormaliteter, enten i form av ipsilateralt postganglionært Horners syndrom eller Adies pupill (16).

Så vidt vi vet er det tidligere kun beskrevet to pasienter (en voksen og et barn) med Harlekins tegn, Adies pupill og normale reflekser, slik som hos vår pasient $(11,18)$. Begge disse hadde bilateral tonisk pupill.

I noen tilfeller er det funnet underliggende strukturelle forklaringer ved disse tilstandene, som slag i hjernestammen (16), nevrovaskulær konflikt (9), okklusjon av anterior radikulær arterie (15) eller karotisdisseksjon (11), men de aller fleste tilfellene er idiopatiske og benigne. En teori er at dysautonomien skyldes skader på perifere autonome og dorsale rotganglier som alle er derivater fra nevrallisten (12).

Denne pasienthistorien lærer oss altså at Harlekins syndrom, Adies pupill og Ross' syndrom representerer et spektrum av partielle dysautonomier (12). Grundig kartlegging av symptomer og funn kan identifisere den anatomiske lokaliseringen av skaden hos noen, men ikke hos alle. De fleste tilfellene er idiopatiske og har et benignt forløp, men likevel anbefales oftalmologisk, nevrologisk og generell undersøkelse, supplert med målrettede supplerende undersøkelser, for å avdekke eventuelle underliggende strukturelle patologiske forhold.

Pasienten har gitt samtykke til at artikkelen blir publisert.

\section{Lars Jørgen Garstad (f. 1985)}

er lege i spesialisering.

Forfatter har fylt ut ICMJE-skjemaet og oppgir

ingen interessekonflikter.

\section{Åse Mygland (f. 1958)}

er spesialist i nevrologi, overlege og professor II. Forfatter har fylt ut ICMJE-skjemaet og oppgir ingen interessekonflikter.

\section{Unn Ljøstad (f. 1962)}

er spesialist i nevrologi, overlege og professor II. Forfatter har fylt ut ICMJE-skjemaet og oppgir ingen interessekonflikter.

\section{Litteratur}

1. Lam BL, Thompson HS, Corbett JJ. The prevalence of simple anisocoria. Am J Ophthalmol 1987; 104: 69-73

2. Nevrologiske prosedyrer.

http://nevro.legehandboka.no/ (26.10.2016).

3. Shin RK, Cheek AG. Teaching Neurolmages: Positive apraclonidine test in Horner syndrome. Neurology 2011; 76: e100.

4. Davis JL, Stewart T, Brazik E et al. The effect of topical administration of atropine sulfate on the normal equine pupil: influence of age, breed and gender. Vet Ophthalmol 2003; 6: 329-32.

5. Kerty E. Nevrooftalmologi. I: Gjerstad L, Hunsbeth Skjeldal O, Helseth E. Nevrologi og nevrokirurgi. 4. utg. Kap. 37. Oslo: Vett og viten, 2014: 491-504.

6. Leavitt JA, Wayman LL, Hodge DO et al. Pupillary response to four concentrations of pilocarpine in normal subjects: application to testing for Adie tonic pupil. Am J Ophthalmol 2002: 133: 333-6.

7. Bourgon P, Pilley FJ, Thompson HS. Cholinergic supersensitivity of the iris sphincter in Adie's tonic pupil. Am J Ophthalmol 1978; 85: 373-7.

8. Alstadhaug KB. Ervervet Horners syndrom. Tidsskr Nor Legeforen 2011: 131: 950-4

9. Wasner G, Maag R, Ludwig J et al. Harlequin syndrome - one face of many etiologies. Nat Clin Pract Neurol 2005; 1: 54-9.

10. Raza N, Dar N, Mustafvi S et al. Ross syndrome with generalized anhidrosis and localized disabling compensatory hyperhidrosis. Ann Saudi Med 2008 28: $53-4$

11. Jain P, Arya R, Jaryal A et al. Idiopathic harlequin syndrome: a pediatric case. J Child Neurol 2013; 28: $527-30$

12. Shin RK, Galetta SL, Ting TY et al. Ross syndrome plus: beyond Horner, Holmes-Adie, and harlequin Neurology 2000; 55: $1841-6$

13. Ross AT. Progressive selective sudomotor denervation; a case with coexisting Adie's syndrome. Neurology 1958; 8: 809-17.

14. Nolano M, Provitera V, Perretti A et al. Ross syndrome: a rare or a misknown disorder of thermoregulation? A skin innervation study on 12 subjects. Brain 2006; 129: 2119-31.

15. Lance JW, Drummond PD, Gandevia SC et al. Harlequin syndrome: the sudden onset of unilateral flushing and sweating. J Neurol Neurosurg Psychiatry 1988; 51: 635-42.

16. Bremner F, Smith S. Pupillographic findings in 39 consecutive cases of harlequin syndrome. J Neuroophthalmol 2008; 28: $171-7$.

17. Guilloton L, Demarquay G, Quesnel L et al. Syndromes dysautonomiques du visage avec signe et syndrome d'Harlequin : étude de trois cas et revue de la littérature. Rev Neurol (Paris) 2013; 169: 884-91.

18. Kalapesi FB, Krishnan AV, Kiernan MC. Segmental facial anhidrosis and tonic pupils with preserved deep tendon reflexes: a novel autonomic neuropathy. J Neuroophthalmol 2005; 25: 5-8. 